\section{The prevalence of ocular disease in chronic lymphocytic leukaemia}

\begin{abstract}
Aim Previous surveys of ocular disease in leukaemia patients have shown the retina, choroid, and orbit as the most commonly involved sites. Depending on the type of leukaemia and the study design, the prevalence of ocular disease in leukaemia varies from 30 to $90 \%$. Although chronic lymphocytic leukaemia (CLL) is the most common leukaemia in Western countries, the prevalence of ocular disease in CLL is not known. The aim of this prospective study was to estimate the prevalence of ocular disease in CLL.

Patients and Methods All CLL patients attending either a teaching or district general hospital haematology clinic were invited to undergo a full eye examination. The clinical stage of the CLL (Binet) at the time of the eye examination and the most recent full blood count (FBC) indices were recorded for each patient.
\end{abstract}

Results Over 6 months, 25 patients with an average age of 65 were recruited. A total of 18 patients had Binet stage A disease, three had stage $B$, and four stage $C$. The mean FBC indices at the time of examination were haemoglobin $13.5 \mathrm{~g} / \mathrm{dl}$, white cell count $37.4 \times 10^{9} / 1$, and platelets $172 \times 10^{9} / 1$. Only three patients $(\mathbf{1 2 \%})$ had ocular disease that was likely to be a secondary complication of CLL. These secondary complications included bilateral posterior subcapsular cataract following radiotherapy, unilateral acute retinal necrosis, and unilateral conjunctival vascular anomalies. The presence of ocular complications was not related to the CLL stage or to the current FBC parameters.

Discussion This study demonstrates that ocular involvement in CLL is uncommon, a reflection of the indolent course of CLL as compared to other leukaemias. Although sight-threatening ocular complications have been documented in this and other studies, the low prevalence of complications and the lack of association with disease parameters make it impossible to identify a 'high-risk' group. Routine screening of CLL patients for ocular complications is not justified.

Eye (2003) 17, 27-30. doi:10.1038/

sj.eye. 6700277

Keywords: chronic lymphocytic leukaemia; complications; screening

\section{Introduction}

There have been several published series and review articles concerning the ophthalmic complications of the leukaemias. However, depending on the type of leukaemia and the study design, the estimated prevalence of ocular disease varies from $30 \%$ to $90 \%$. $^{1}$ Of all leukaemia patients, about $5 \%$ have been reported to develop visual loss attributable to the underlying condition. ${ }^{2}$ Chronic lymphocytic leukaemia (CLL) is the most common leukaemia in Western countries. ${ }^{1}$ Ocular involvement in CLL can either be direct via leukaemic infiltrate ${ }^{3}$ or indirect as a consequence of compromised immune function, hyperviscosity, thrombocytopaenia, anaemia, or indeed the treatment of CLL. ${ }^{4-6}$ To our knowledge, the published literature does not provide any subgroup analysis of the complications based on classification of the leukaemia, nor has there been any study looking specifically into CLL. Having previously identified a few individual patients with ocular complications of CLL, we planned to determine the nature and extent of ocular complications and see if routine screening of CLL patients for ocular disease is justified.

\section{Patients and methods}

In a prospective study, all CLL patients attending either a teaching or district general
${ }^{1}$ Department of Ophthalmology St James's University Hospital

Leeds, UK

${ }^{2}$ Department of Ophthalmology Huddersfield Royal Infirmary Lindley, UK

Correspondence: M McKibbin Department of Ophthalmology St James's University Hospital Beckett Street Leeds LS9 7TF, UK Tel: + 441132433144 Fax: + 441132065028 E-mail: martinmckibbin@ cswebmail.com 
hospital haematology clinic were invited to undergo an eye examination, which included clinical examination of the ocular adnexae and slit-lamp examination of the anterior and posterior segments. The clinical (Binet) stage of the CLL and the most recent full blood count (FBC) indices were recorded for each patient at the time of examination (Table 1). ${ }^{7}$ Ocular abnormalities were classified as follows:

- primary ocular complications likely to result from leukaemic infiltrate;

- secondary ocular complications likely to result from systemic therapy or haematological disturbance such as anaemia or immune deficiency;

- miscellaneous ocular abnormalities/disease unrelated to CLL.

A literature search was also performed to identify relevant case reports, series, or review articles. Ethical Committee approval was obtained prior to beginning the study.

\section{Results}

Over a 6-month period, 25 patients were recruited. The average age was 65 years (range $45-88$ years). Prior therapy for CLL had been given to 11 patients with one or a combination of cytotoxic agents, steroids, total body irradiation, and bone marrow transplantation. At the time of examination, 18 patients had Binet stage $\mathrm{A}$ disease, three had stage $B$, and four stage $C$ (Table 2). The mean FBC indices at the time of examination were as follows: haemoglobin $13.5 \mathrm{~g} / \mathrm{dl}$ (range 10-16), white cell count $37.4 \times 10^{9} / 1$ (range 4.5-123.4), and platelets $172 \times 10^{9} / 1$ (range 41-319).

No patients had direct primary leukaemic complications. Three patients (12\%) had ocular disease, which was likely to be an indirect secondary complication of CLL. These secondary complications included bilateral posterior subcapsular cataract, unilateral retinal necrosis, and unilateral conjunctival vascular anomalies. Although each of these three patients had required prior CLL therapy, no obvious association between these ocular complications and either the

Table 1 Binet staging for CLL

\begin{tabular}{ll}
\hline Stage A & $\begin{array}{l}\text { No anaemia or thrombocytopaenia and less than } \\
\text { three enlarged lymph node areas }\end{array}$ \\
Stage B & $\begin{array}{l}\text { No anaemia or thrombocytopaenia but with three } \\
\text { or more enlarged lymph node areas }\end{array}$ \\
Stage C & $\begin{array}{l}\text { Anaemia (haemoglobin }<10 \mathrm{~g} / \mathrm{dl} \text { ) and } / \text { or } \\
\left.\text { thrombocytopaenia (platelets }<100 \times 10^{9} / \mathrm{l}\right)\end{array}$ \\
\hline
\end{tabular}

current Binet stage or any of the recent FBC indices could be demonstrated. Miscellaneous ocular abnormalities were present in 13 patients (52\%) (Table 2).

\section{Discussion}

Prior to the use of bone marrow biopsy, the ophthalmologist was often called upon to assist with the diagnosis and management of the patient with leukaemia. ${ }^{1}$

Nowadays with the ready availability of FBC estimation and the resultant increased pick-up of earlier disease, up to $60 \%$ of CLL patients may be asymptomatic at the time of diagnosis. These patients often do not require treatment. ${ }^{8}$ In others, disease progression leads to lymph node enlargement, hepato-splenomegaly and complications such as autoimmune cytopaenia and infection. Therapy for CLL is determined by the patient's symptoms and signs, and the clinical stage may change with the disease duration and with therapy. ${ }^{9}$ Treatment modalities include chemotherapy with steroids and cytotoxic agents, immunotherapy and allo- or autotransplantation of bone marrow with total body irradiation. ${ }^{8,9}$ All ocular structures may be involved in the leukaemic process. In CLL, ocular involvement has been reported in the orbit, optic nerve, retina, vitreous, anterior segment, and conjunctiva..$^{3-6,10}$ Most of the patients in our series had miscellaneous ocular disease but three patients $(12 \%)$ had ocular complications of CLL. As mentioned, leukaemic complications can be best viewed as either direct or indirect. In our series, the involvement was exclusively indirect: one case as a consequence of treatment, the other two explicable as sequelae of the disorder of haematological parameters or function. A 57-year-old male developed bilateral posterior subcapsular cataract 2 years after total body irradiation, but retained a corrected acuity of $6 / 6$ in both eyes (Figure 1). Comma-shaped conjunctival vascular anomalies were noted in one eye of a 73-year-old male, previously treated for Binet stage $\mathrm{C}$ disease (Figure 2). These conjunctival anomalies have been described previously. ${ }^{11}$ Acute retinal necrosis had previously developed in one eye of a 72-year-old male, while he was receiving a course of chemotherapy with chlorambucil for Binet stage $C$ disease and had a white cell count of $4.9 \times 10^{9} / 1$. Despite antiviral therapy and posterior segment surgery, the final acuity in the affected eye was no perception of light. Although acute retinal necrosis occurs most commonly in the immunocompetent, an identical disease has been recognised in immunosuppressed patients. ${ }^{7}$ There was no clear association between the presence of these ocular complications and the Binet stage or the FBC indices. 
Table 2 Binet stage, FBC parameters, and ocular abnormalities for the 25 CLL patients examined

\begin{tabular}{|c|c|c|c|c|}
\hline Binet stage & $H b(g / d l)$ & WCC $\left(\times 10^{9} / l\right)$ & Platelets $\left(\times 10^{9} / l\right)$ & Ocular abnormalities \\
\hline A & 13.9 & 4.5 & 99 & Bilateral posterior subcapsular cataract \\
\hline A & 14.2 & 5.1 & 178 & \\
\hline A & 14.4 & 8.9 & 195 & Pseudophakia \\
\hline A & 14.5 & 13 & 170 & Myopia, exotropia \\
\hline A & 12 & 13.2 & 255 & Thyroid-associated orbitopathy \\
\hline A & 13 & 13.2 & 319 & \\
\hline A & 13.2 & 20.5 & 256 & \\
\hline A & 15.5 & 30.1 & 208 & Primary open-angle glaucoma \\
\hline A & 12.1 & 33 & 185 & Amiodarone keratopathy, pseudophakia \\
\hline A & 13.3 & 44.1 & 297 & Age-related macular degeneration \\
\hline A & 16 & 63.8 & 176 & \\
\hline A & 14.1 & 69.9 & 192 & Age-related macular degeneration \\
\hline A & 13.6 & 76 & 42 & Myelinated fibres, retinoschisis \\
\hline A & 11.3 & 123.4 & 103 & Pseudophakia \\
\hline A & 12.9 & 39.1 & 133 & \\
\hline A & 14.1 & 35.7 & 208 & \\
\hline $\mathrm{B}$ & 12.7 & 6.1 & 215 & \\
\hline $\mathrm{B}$ & 15.3 & 17.8 & 125 & Conjunctival vascular anomaly \\
\hline B & 14.4 & 92.1 & 179 & \\
\hline $\mathrm{C}$ & 14.4 & 5.4 & 93 & \\
\hline $\mathrm{C}$ & 10 & 11.7 & 112 & Unilateral acute retinal necrosis \\
\hline $\mathrm{C}$ & 12.4 & 12.7 & 200 & \\
\hline $\mathrm{C}$ & 12.4 & 81.6 & 104 & Angioid streaks \\
\hline
\end{tabular}

$\mathrm{Hb}$, haemoglobin; WCC, white cell count.

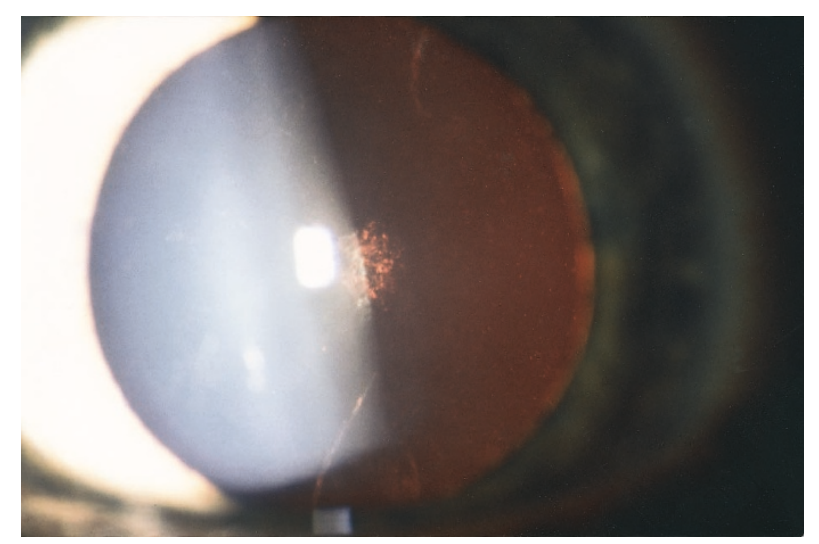

Figure 1 Posterior subcapsular cataract in a 57-year-old male, 2 years after total body irradiation.

In other forms of leukaemia, the retina is the most common site of ocular involvement. Dilated retinal veins, vascular sheathing, retinal haemorrhage, cotton wool spots, Roth spots, and microaneurysms are frequent findings. ${ }^{1,2}$ On histological examination,

microaneurysms have been reported in up to $30 \%$ of CLL patients and choroidal infiltrate may be at least as common. ${ }^{1,13}$ None of the patients in this series had evidence of retinal vascular or choroidal involvement on clinical examination. Such involvement may have been

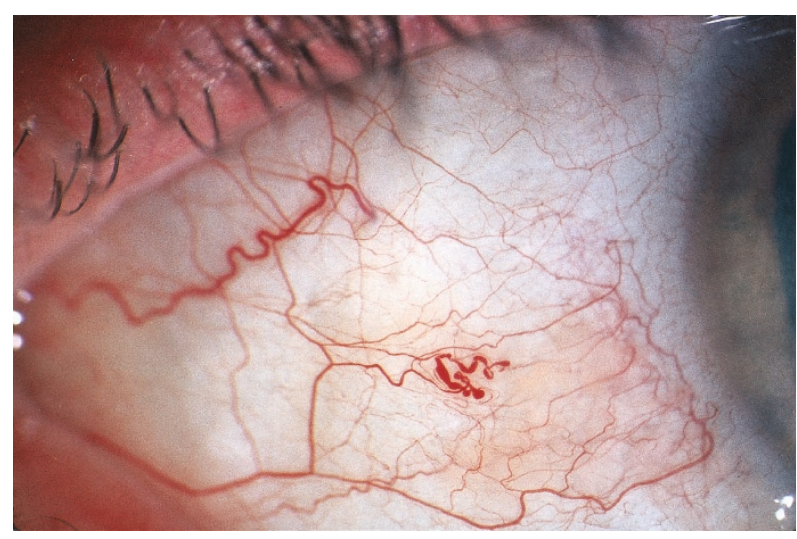

Figure 2 Comma-shaped conjunctival vascular anomalies in a 73-year-old man with Binet stage B disease.

detectable on fluorescein angiography but this procedure did not seem justified.

In this study, the patients recruited are likely to be representative of the CLL case mix in most haematology clinics, and the results reflect the prevalence of ocular disease at a single point in time. Although miscellaneous ocular disease was common, this reflects the age of the study group. The prevalence of sight-threatening ocular complications in CLL patients is low, and overall this study demonstrates a lower than expected rate of ocular 
3 Currie JN, Lessell S, Lessell IM, Weiss JS, Albert DM, Benson EM. Optic neuropathy in chronic lymphocytic leukemia. Arch Ophthalmol 1988; 106(5): 654-660.

4 Hattenhauer MG, Pach JM. Ocular lymphoma in a patient with chronic lymphocytic leukemia. Am J Ophthalmol 1996; 122(2): 266-268.

5 Kalina PH, Campbell RJ. Aspergillus terreus endophthalmitis in a patient with chronic lymphocytic leukemia. Arch Ophthalmol 1991; 109(1): 102-103.

6 Haider A, Hassett P. Chronic lymphocytic leukaemia in the elderly. Br J Ophthalmol 1995; 79(4): 395.

7 Binet R, Auquier, Dighiero G et al. A new prognostic classification of chronic lymphocytic leukemia derived from a multivariate survival analysis. Cancer 1981; 48: 198-206.

8 Mead GM. Malignant lymphomas and chronic lymphocytic leukaemia. BMJ 1997; 314: 1103-1107.

9 Rozman CR, Montserrat E. Chronic lymphocytic leukemia. N Engl J Med 1995; 333(16): 1052-1057.

10 Scully RE. Weekly clinicopathological exercises. N Engl J Med 1991; 325(7): 494-504.

11 Swartz M, Jampol LM. Comma-shaped vascular segments of conjunctiva in chronic granulocytic leukemia. Can J Ophthalmol 1975; 10: 458-461.

12 Duker JS, Blumenkranz MS. Diagnosis and management of the acute retinal necrosis syndrome. Surv Ophthalmol 1991; 35: 327-343.

13 Duke JR, Wilkinson CP, Sigelman S. Retinal microaneurysms in leukaemia. Br J Ophthalmol 1968; 52 368-374.

14 Davis JPL, Crombie IK, Davies HTO. Understanding screening: requirements for a successful programme. Hospital Med (London) 2001; 62(2): 104-107.

15 Guyer DR, Schachat AP, Vitale S, Markowitz JA, Braine H, Burke PJ et al. Leukemic retinopathy. Relationship between fundus lesions and haematological parameters at diagnosis. Ophthalmology 1989; 96(6): 860-864.

16 Leonardy JL, Rupani M, Dent G, Klintworth GK. Analysis of 135 autopsy eyes for ocular involvement in leukemia. Am J Ophthalmol 1990; 109: 436-444.
1 Kincaid MC, Green WR. Ocular and orbital involvement in leukemia. Surv Ophthalmol 1983; 27(4): 211-232.

2 Schachat AP, Markowitz JA, Guyer DR, Burke PJ, Karp JE, Graham ML. Ophthalmic manifestations of leukemia. Arch Ophthalmol 1989; 107: 697-700. 